Rev. Elet. em Gestão, Educação e Tecnologia Ambiental (e-ISSN: 2236-1170)

\title{
MODELO DE USO E OCUPAÇÃO DA PAISAGEM NO MUNICÍPIO DE GARANHUNS-PE
}

\author{
Felippe Pessoa de Melo'

\begin{abstract}
${ }^{1}$ Formado em Geogrfia pela Universidade de Pernambuco-UPE, com Pós-Graduação Lato Sensu em Programação do Ensino de Geografia pela mesma instituição e Mestrando em Geociências e Análise de Bacias pela Universidade Federal de Sergipe-UFS.
\end{abstract}

http://dx.doi.org/10.5902/223611707857

\section{RESUMO}

Tendo como subsídio o geoprocessamento foi realizado um mapeamento cartográfico do espaço geográfico de Garanhuns-PE, o qual tinha como objetivo compreender a atual configuração espacial da paisagem e suas correlações com a degradação ambiental. Com base nas informações de gabinete e campo, foi identificar que o espaço está organizado de maneira insustentável. Logo existem poucas áreas verdes preservadas no perímetro urbano, a zona de expansão urbana está avançando para os vales, à flora remanescente fora da paisagem urbana é de mata secundária e está sendo minimizada por causa da expansão dos pastos e atividades de subsistência.

Palavras chave: Geoprocessamento, expansão urbana e insustentável.

\begin{abstract}
With the grant was made a geoprocessing cartographic mapping of the geographical space of Garanhuns-PE, which was aimed at understanding the current spatial configuration of the landscape and its correlations with environmental degradation. Based on information from the office and field, was to identify which space is organized in an unsustainable manner. Soon there few preserved green areas within the city limits, the area of urban expansion is advanced into the valleys, flora remaining outside the urban landscape is of secondary forest and is being minimized because of the expansion of grazing and subsistence activities.
\end{abstract}

Keywords: Geoprocessing, urban sprawl and unsustainable.

\section{INTRODUÇÃO}

Utilizando as tecnologias atreladas ao geoprocessamento, foi possível formar um banco de dados geográficos georreferenciados, o qual subsidiou a compreensão do modelo de uso e ocupação do espaço geográfico pela sociedade garanhuense.

Para Câmara et al. (2001) a coleta de informações sobre a distribuição geográfica de recursos minerais, propriedades, animais e plantas sempre foi uma parte importante das atividades das sociedades organizadas. Até recentemente, no entanto, isto era feito apenas em documentos e mapas em papel, isto impedia uma análise que combinasse diversos mapas e dados. Com o desenvolvimento simultâneo, na segunda metade do século passado da tecnologia 
Rev. Elet. em Gestão, Educação e Tecnologia Ambiental (e-ISSN: 2236-1170)

de informática, tornou-se possível armazenar e representar tais informações em ambiente computacional, abrindo espaço para o aparecimento do Geoprocessamento.

Que é uma tecnologia interdisciplinar, que permite a convergência de diferentes disciplinas científicas para o estudo de fenômenos ambientais e urbanos. Ou ainda, que "o espaço é uma linguagem comum" para as diferentes disciplinas do conhecimento. O que facilita a compilação e interpretação dos dados obtidos pelo SIG.

Analisando essas informações foi possível confeccionar uma carta geográfica que contém as informações referentes a atual configuração geoespacial de Garanhuns-PE. Dessa forma na área de estudo foram encontradas seis categorias distintas de uso e ocupação, sendo elas: Mata remanescente, Pastos e Agricultura de subsistência, Zona de expansão urbana, Áreas residenciais, comerciais e industriais. Com a finalidade de confirmar, corrigir e reambular os dados, foi realizada uma atividade de campo e logo em seguida os ajustes necessários na carta para posterior análise e interpretação das informações.

Ficando evidenciado que a área em questão apresenta resquícios de mata, os quais estão sendo paulatinamente removidos para ceder espaço para zona de expansão urbana e ampliação de áreas para pastagens e agricultura de subsistência. O perímetro residencial está se verticalizando e crescendo em direção as encostas do modelado devido a crescente demanda por novos lotes residenciais. O centro comercial principal está localizado na porção noroeste do sítio urbano e o secundário a nordeste. Estando o setor secundário ativo localizado a sudoeste da área urbana.

Para minimizar esses problemas geoespaciais é necessária a implantação de uma modelo sustentável, permitindo assim que o ambiente seja utilizado de forma que ele possa se recuperar.

Para Gois (2010) o planejamento ambiental pode se apresentar sob diferentes formas de expressão, sendo que os termos zoneamento territorial ambiental, os estudos de impactos ambientais, planos de manejo de bacias hidrográficas e capacidade agrícola das terras são apenas instrumentos do planejamento ambiental.

Santos (2004) afirma que a avaliação de impactos ambientais é outro instrumento de planejamento ambiental, pois a avaliação constrói cenários futuros e pressupõe a participação pública.

A área de estudo está localizada no nordeste brasileiro, estando delimitado pelos: paralelos de $8^{\circ} 51^{\prime} 37^{\prime \prime} / 8^{0} 55^{\prime} 40^{\prime \prime}$ S e meridianos de $36^{\circ} 26^{\prime} 6^{\prime \prime} / 36^{\circ} 30^{\prime} 52^{\prime \prime}$ W (Figura 01). 


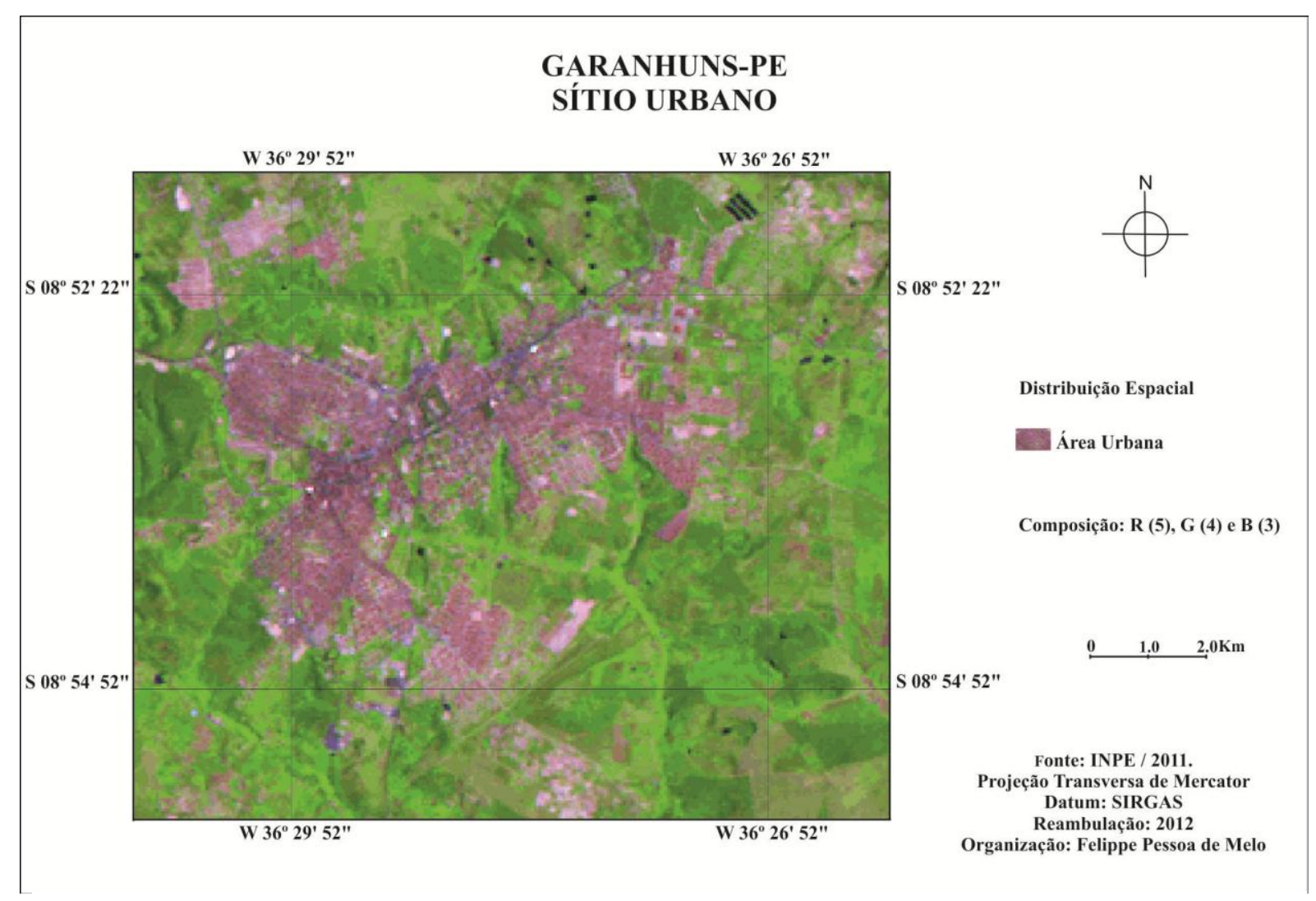

Figura 01. Localização da área de estudo.

\section{METODOLOGIA}

Em um primeiro momento realizou-se a atividade de campo, com a finalidade de coletar informações pertinentes à pesquisa.

Em gabinete foi utilizando o SIG SPRING, para confecção de um banco de dados geográficos digitais georreferenciados, com o sistema de coordenadas geográficas e datum SIRGAS, zona -24. Utilizando o SIG foi realizada a importação das imagens Landsat 5 (2010), sensor TM, como resolução espacial de $30 \mathrm{~m}$, para categoria imagem. Logo em seguida realizou-se a composição colorida (RGB), e confecção de uma IMG sintética.

A próxima etapa foi à vetorização dos polígonos na categoria temática o que possibilitou delimitar as categorias de análise do espaço e realizar os cálculos de superfície, posteriormente ocorreu a exportação das informações para o SCARTA, nele foi confeccionada a carta Uso do Solo na escala de 1:1000.

De posse desse material realizou-se a fotointerpretação, essa fase do trabalho teve como objetivo a interpolação dos dados obtidos na pesquisa de campo e em gabinete. Com o propósito de efetuar a reambulação das informações decorrentes da fotointerpretação. Proporcionando ajustes nas cartas desenvolvidas, quando necessários. Para posterior análise, interpretação dos dados provenientes desse material. Dessa forma a pesquisa apresentará dados com um maior grau de coesão e coerência com os fenômenos que estão ocorrendo no espaço geográfico. 


\section{RESULTADOS E DISCUSSÕES}

Através das tecnologias do Sensoriamento Remoto e SIG, foi confeccionada a carta temática de Uso do Solo de Garanhuns-PE (Figura 02).

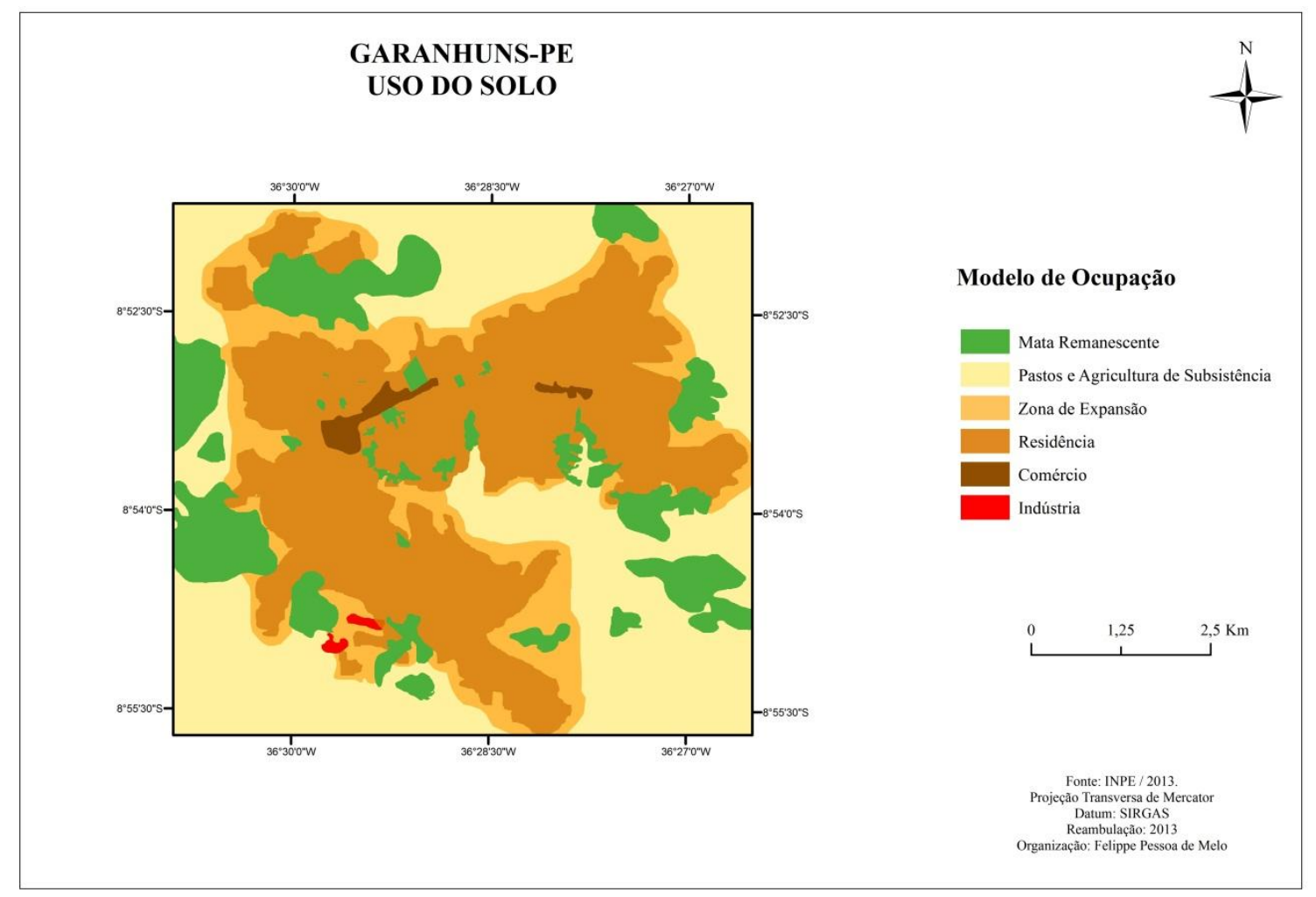

Figura 02. Modelo de ocupação da paisagem.

Realizando a análise e interpretação das informações provenientes da carta Uso do Solo, ficou evidenciado que o perímetro urbano apresenta uma área de $227 \mathrm{Km}^{2}$, dos quais $5.53 \mathrm{Km}^{2}$ são representados pelos dois centros comerciais.

Comparando com sua extensão urbana em 1982 que era de $76.43 \mathrm{~km}^{2}$, em um intervalo temporal de 22 anos ocorreu um aumento de $150.57 \mathrm{Km}^{2}$, ou seja, $51.71 \%$. Esse ritmo elevado de crescimento ocorre principalmente pelo papel de polo regional que o município exerce na região e devido à política de erradicação do café implantada pelo Instituto Brasileiro do Café-IBC em áreas com baixas produtividades. Logo era empregada pouca tecnologia na cafeicultura, tendo com consequência direta a necessidade de grandes quantidades de mão de obra.

A substituição dessa monocultura foi feita pela pecuária leiteira, atividade que exige menos mão de obra que a cafeicultura. Dessa forma os habitantes da zona rural migram em direção ao centro urbano do município de Garanhuns-PE, em busca de novas oportunidades de emprego.

Deve-se ressaltar que esse novo modelo agrário também impactou outras atividades agrícolas, forçando a redução das lavouras e maximização dos campos para pastagens (Tabela 01). 
DE MELO, v(10), no 10, p. 2198-2207, JAN-ABR, 2013.

Rev. Elet. em Gestão, Educação e Tecnologia Ambiental (e-ISSN: 2236-1170)

\begin{tabular}{c|c|c|c|c}
\hline Ano & Lavoura (ha) & Decréscimo (\%) & Pastagem (ha) & Crescimento (\%) \\
\hline 1960 & 48.47 & ---- & 27.78 & ---- \\
\hline 1970 & 38.31 & 21.39 & 47.76 & 71.92 \\
\hline 1975 & 32.84 & 14.27 & 53.08 & 11.13 \\
\hline
\end{tabular}

Tabela 01 - Relação entre as áreas de lavouras e pastagens.

Fonte: $<$ http://www.ibge.gov.br>. Acesso: 20/03/2012.

Analisando a tabela (01), observa-se que da década de 60 a 70 as áreas para plantio de lavouras diminuiu $35.66 \%$. Já o perímetro das pastagens no mesmo espaço de tempo maximizou 83.05\%.

A reterritorialização do espaço geográfico do município ocorreu de forma brusca com a introdução da criação de gado leiteiro com fins comerciais. Essa falta de planejamento público e privado culminou ao longo das décadas em um cenário rural marcado pelo êxodo rural e um perímetro urbano sem a infraestrutura necessária para atender os setores da economia e as necessidades da população em crescente aumento. Destacando-se a falta de: saneamento ambiental, áreas de lazer, local adequado para tratamento dos resíduos residenciais, comerciais e industriais.

Sua zona de expansão urbana tem uma área de $68.86 \mathrm{~km}^{2}$, sendo que devido à falta de áreas adequadas para instalação das residências, o perímetro urbano está crescendo em direção as encostas instáveis do modelado.

Azambuja (2007) afirma que o perímetro urbano está totalmente situado no domínio dos Latossolos Amarelos, os quais são constituídos por minerais altamente intemperizados e argila de baixa atividade, ou argila do tipo 1:1. Seus perfis alcançam em geral espessuras superiores a 2 metros, com horizontes B latossolico profundo. A formação de micro-agregados no horizonte B proporciona a estes solos alta porosidade, permitindo dessa maneira uma maior condutibilidade de água, o que por sua vez amplia o risco geomorfológico, quando saturados em áreas de encostas urbanas.

Ocorre ainda associado aos Latossolos Amarelos a presença dos Argissolos no entorno urbano. Em termos genéticos estes Argissolos podem ser considerados antigos Latossolos em processo de podzolização. A não funcionalidade destes solos de caráter herdados, sob condições climáticas atuais, atribui aos Argissolos uma maior sensibilidade, facilitando a ocorrência de erosão laminar, linear e movimentos de massa.

A flora remanescente ocupa $101.76 \mathrm{Km}^{2}$ do território, sendo que dentro da área urbana só existem resquícios de cobertura vegetal, maximizando a absorção do calor, o que provoca uma sensação térmica desconfortável na população.

Visando minimizar a sensação de calor e melhorar a estética da paisagem, introduziu-se a flora exótica na localidade, as principais espécies introduzidas foram o Pinheiro-do-Paraná (Araucaria angustifolia), Castanhola (Terminalia catappa), Espécies de Eucaliptos (Eucalyptus), Nim da Índia (Azadirachta indica).

O Nim da Índia é a variedade que possui a maior aceitação pela população, por apresentar um índice de crescimento que oscila entre 4 e $7 \mathrm{~m}$ nos primeiros anos, o que é bem mais rápido que o das espécies nativas, sua copa pode atingir até $12 \mathrm{~m}$, seu tronco é quase retilíneo e pode chegar aos $20 \mathrm{~m}$, possui um sistema radicular que pode chegar aos $15 \mathrm{~m}$ de profundidade o que facilita sua sobrevivência em períodos com escassez de água. Essas são as principais características que levam a população a optar por essa árvore. 
Rev. Elet. em Gestão, Educação e Tecnologia Ambiental (e-ISSN: 2236-1170)

Levando em consideração que as casas das comunidades pobres apresentam calçadas com uma média 1,5m de largura o plantio dessa árvore vai ocasionar um problema na estrutura dessas casas em um intervalo temporal bem curto.

O setor secundário $1.28 \mathrm{Km}^{2}$, destacando a indústria Bom Gosto/SA que absorve parte da produção leiteira da região.

Já as porções da paisagem ocupadas por pastos e agricultura de subsistência possui uma área de $193.95 \mathrm{Km}^{2}$. Sua grande extensão deve-se principalmente por causa da criação de gado leiteiro.

Em relação à agricultura familiar está sendo praticada nas encostas dos vales, sendo que esse tipo de prática agrícola nesse ambiente desestabiliza o solo, tornando-o mais susceptível a deslizamentos e desmoronamentos. Para tentar controlar esses processos são despejados restos de materiais oriundos da construção civil nas áreas com maior sensibilidade aos agentes erosivos. Mas essas medidas são apenas paliativas, quando chega à estação chuvosa os movimentos de massas se intensificam, colocando a população em risco.

Segundo Rosa (2005) as enxurradas além de transportarem o material não consolidado ou as partículas de solo desagregadas pelo impacto das chuvas, também agem como força de erosão pelo caminho no qual passam. A forma de administrar ou controlar locais com risco de deslizamento ou desmoronamento segue duas vertentes fundamentais: a primeira é previsão, que permite localizar áreas de risco, indicando possíveis locais onde podem ocorrer acidentes, e a segunda é a prevenção, que são medidas com a finalidade de evitar ou reduzir os impactos do local.

As porções mais abertas dos vales são aproveitadas para realização da pecuária extensiva, reaproveitando as águas dos esgotos sem o devido tratamento como fonte de água permanente para o gado. Essa drenagem encaixa-se em áreas esculpidas por cursos de águas temporárias ou permanentes.

Esse tipo de prática provoca doenças de veiculação hídricas no gado, o qual será abatido para o consumo da população. Podendo vir a provocar problemas como disenteria, giardíase, hepatite A, cólera, febre tifoide...

Germano et al. (2001) explica que a demanda de água representa um grave problema, pois além do enorme volume consumido e desperdiçado, nem sempre a restituição do produto ao meio natural, sem tratamento prévio, está isenta de riscos à saúde e ao próprio ambiente. É o que acontece com a contaminação e a poluição provocadas pelos efluentes domésticos, públicos e industriais, lançados diretamente nos cursos d'águas. 0 mesmo se aplica para resíduos químicos provenientes de adubos, defensivos agrícolas e inseticidas, comumente utilizados nas práticas agrícolas e pecuárias, e que mediante as precipitações pluviométricas alcançam, por escoamento, os lençóis freáticos, os rios e os lagos naturais ou artificiais, colocando em risco a sobrevivência de qualquer forma de vida nesses ecótopos.

Para minimizar os impactos da rede hidrográfica urbana no modelado os órgãos governamentais realizam obras de infraestrutura, mas elas não levam em consideração as peculiaridades físicas do local, contribuindo para problemas estruturais nessas obras e agravando os movimentos de massas no perímetro.

Os problemas provenientes do crescimento urbano em direção as áreas de encostas, podem ser minimizados através de um planejamento urbano que leve em consideração os aspectos físicos do modelado, proporcionando sua ocupação de forma sustentável.

Os movimentos de massas na zona urbana de Garanhuns são responsáveis por uma grande quantidade de problemas de ordem social, econômica e ambiental. 
Rev. Elet. em Gestão, Educação e Tecnologia Ambiental (e-ISSN: 2236-1170)

Conforme Bonuccelli et al. (1999) as tentativas de solucionar ou minimizar os problemas relacionados aos movimentos de massa deve-se proceder primeiramente ao levantamento dos processos, levantamento das características do meio físico, zoneamento ou hierarquização das áreas sujeitas à ocorrência de movimentos de massa e processos correlatos, permitindo assim, uma previsão de futuros problemas e intervenções.

Dentro desse cenário de risco geoambiental, destacam-se no sítio urbano de Garanhuns as comunidades Liberdade, Heliópolis, Novo Heliópolis, Parque Fênix, COHAB III, São José, Barreira do Inferno, Santo Antônio, Jardim Petrópolis e Magano.

A comunidade da Liberdade está instalada na borda leste do vale da Liberdade popularmente chamado de Buracão, as encostas dessa área estão desestabilizadas devido à retirada da cobertura vegetal nativa para ampliação do perímetro urbano sem a devida infraestrutura. O sistema de esgoto dessas casas é estruturado de maneira que os dejetos orgânicos são armazenados em fossas individuais ou coletivas nas encostas ou são jogados diretamente nas vertentes. Em ambos os modelos de descarte dos resíduos o geoambiente é prejudicado com a contaminação e saturação do solo. As porções mais íngremes das vertentes que não são ocupadas com moradias são aproveitadas para realização de atividades agrárias com ênfase para o cultivo de banana, feijão, milho, criação de animais de pequeno porte como galinhas, cabras, suínos... O fundo do vale é ocupado com o mesmo modelo agrícola acima exemplificado e com a criação de gado de corte e leiteiro. O modelo de ocupação do espaço geográfico implantado por essa comunidade provoca interferências na topografia local que maximizam a capacidade dos agentes erosivos. Aplicando a classificação de Filho (1992) para movimentos de massas, constata-se que os quatro processos são visivelmente encontrados na localidade em questão. Em 2010 a população que ocupava a área mais crítica dessas encostas foi removida pela Defesa Civil e alocada na COHAB III. Logo em seguida essas moradias foram destruídas para evitar uma nova ocupação, sendo que essa localidade não foi contemplada com procedimentos que possibilitassem sua recuperação ambiental.

O Heliópolis é um bairro que ocupa a borda oeste do vale da Liberdade, seu modelo de uso e ocupação do espaço geográfico ocorre de maneira mais estruturada pois a população que ocupa essa localidade é de alto poder aquisitivo. Seu esgoto é contemplado com um canal que recebe seus dejetos residenciais, o que evita que eles sejam despejados nas encostas do vale, porém essas águas não são tratadas e são despejadas no fundo do vale. Provocando problemas de contaminação no solo. Suas fossas sépticas são bem estruturadas e estão longe de corpos de água, entretanto as casas que estão localizadas nas margens das encostas instalam suas fossas nas proximidades da vertente ou despejam seus dejetos diretamente no sistema de esgoto público. Devido sua infraestrutura, as casas localizadas nessa porção do modelado não apresentam processos erosivos intensos. Apenas as casas que estão mais próximas da vertente é que apresentam movimentos de massas suaves, do tipo rastejo ou creep.

O bairro Novo Heliópolis ocupa as bordas leste e oeste de um vale, ambas as margens são contempladas com um sistema de esgoto o que minimiza os problemas nas encostas. Mas contamina os solos do fundo do vale, logo essas águas são despejadas sem tratamento. As casas que estão localizadas nas encostas e próximas a esse sistema de esgoto público despejam seus dejetos diretamente nele, as demais possuem fossas sépticas individuais. Devido melhorias na infraestrutura dessa área, ela está passando por um processo de valorização imobiliária, tendo como consequência a retirada da cobertura vegetal secundária, para a abertura de novos loteamentos. Essas ações estão desestabilizando as encostas das feições, as moradias que estão mais próximas dessa área já começam a apresentar rachaduras devido o rastejo ou creep. 
Rev. Elet. em Gestão, Educação e Tecnologia Ambiental (e-ISSN: 2236-1170)

A comunidade do Parque Fênix ocupa o lado leste do vale do Novo Heliópolis, a qual está com um processo da flora local bem avançado. Seu esgoto é despejado diretamente nas vertentes desestabilizando as encostas, contaminando os solos... As residências que estão mais afastadas das encostas possuem fossas sépticas individuais ou coletivas. Em relação aos movimentos de massas nessas feições destacam-se os escorregamentos e corridas. Devido à abertura de novos lotes na porção noroeste do bairro ocorreu o processo de desaceleração do processo de urbanização em direção as vertentes.

A COHAB III está situada na porção norte de um vale, devido à falta de um sistema de saneamento adequado, os esgotos são despejados nas margens das vertentes provocando a desestabilização e contaminação dos solos com os dejetos residenciais. As moradias localizadas nas encostas quando não despejam seus dejetos diretamente nessas feições, possuem fossas sépticas artesanais mal estruturadas. As quais quando enchem não são esgotadas com os devidos cuidados. Ao analisar as casas que estão próximas ou nas encostas, nota-se que apresentam rachaduras por causa do rastejo ou creep. No perímetro do bairro encontra-se a presença de sulcos e ravinas encaixados dentro da drenagem oriunda das residências.

O bairro São José apresentava-se como uma área de baixo risco em relação a movimentos de massas em encostas, mas com o processo de construção de prédios residenciais nessa área está ocorrendo de forma inadequada, suas vertentes começam apresentar quedas ou falls. Para maximizar as áreas de ocupação estão sendo feitos cortes retilíneos e escalonados nas encostas. Sem levar em consideração as peculiaridades físicas do local, rápidas transformações nas feições geomorfológicas tendem a ocasionar danos geoambientais.

A comunidade que ocupa a área denominada de Barreira do Inferno está totalmente assentada em uma vertente instável. Não existe saneamento básico, os dejetos residenciais são despejados diretamente na encosta, causando rastejo, escorregamentos, quedas e corridas. Nessa localidade é praticada uma atividade econômica de subsistência (Olaria), o que agrava ainda mais a instabilidade do solo. No período chuvoso é possível acompanhar a rápida ação erosiva, com o surgimento de novos sucos e a transformação dos antigos sucos em ravinas. Com o término do período chuvoso, a população tenta controlar esses processos erosivos colocando restos de construção civil, mas algumas dessas formas são utilizadas como lixão coletivo. Agravando ainda mais os problemas socioambientais.

O Bairro Santo Antônio possui uma parte de suas residências localizadas em uma encosta instável, devido à retirada da cobertura vegetal, alongamento dessa feição sobrepondo camadas de lixo urbano e restos da construção civil, pois essa localidade já foi um lixão público municipal. Com a desativação dele passou-se a sobrepor camadas de argila e restos de construção, com o alongamento dessa área foi realizado um aplainamento e posteriormente a mesma foi subdividida em pequenos lotes para implantação de residências o que cominaria em problemas de instabilidade no solo da localidade. A prefeitura municipal já realizou varias obras de contenção para essa feição, sendo que elas não aguentam os invernos mais rigorosos.

O Magano circunda a área de um vale localizado próximo ao centro da cidade, essa feição apresenta um alto grau de ocupação, mesmo apresentando vertentes íngremes, as quais são aproveitadas para criação extensiva de gado. Em relação aos esgotos, existe um sistema de escoamento público, mas sem tratamento, provocando contaminação no decorrer de seu trajeto. As fossas sépticas são artesanais, não passam por processos de esgotamento individuais e são instaladas nas encostas. Mas existem residências que despejam seus dejetos diretamente no esgoto. No fundo desse vale existe uma área denominada pelos populares de Vila Maria, nela está 
Rev. Elet. em Gestão, Educação e Tecnologia Ambiental (e-ISSN: 2236-1170)

localizada uma das nascentes do Rio Mundaú. A princípio essa água é aproveitada para criação de gado e para lavar roupas na lavanderia pública municipal.

O sítio urbano de Garanhuns apresenta dez localidades críticas em relação à ocupação das encostas. Utilizando a classificação taxonômica de Ross (1992), esse processo de uso e ocupação da paisagem está inserido no sexto táxon (Formas e processos atuais). Em relação aos tipos de movimentos de massas que estão ocorrendo nas encostas, ao aplicar a classificação de Filho (1992) constata-se que essas localidades contemplam os quatro processos de sua classificação.

Os processos de ocupação dessas vertentes tem como ponto comum a falta de planejamento adequado na execução do assentamento residencial, evitando problemas de instabilidade no solo, para ocupar uma encosta de maneira sustentável é necessário compreender suas características físicas, logo dessa forma fica mais fácil traçar modelos e metas de ocupação.

\section{CONCLUSÕES}

O processo de assentamento e ampliação do sítio urbano de Garanhuns-PE não levou em consideração questões políticas e religiosas, desconsiderando as peculiaridades físicas e capacidade de recuperação do geoambiente, o que maximizou a ação dos agentes erosivos, Fenômenos como lixiviamento, assoreamento, formação de sulcos, ravinas, voçorocas, deslizamentos e desmoronamentos, corpos de água contaminados, são de fácil percepção na paisagem.

Utilizando as tecnologias do sensoriamento remoto e SIG para formação de um banco de dados geográficos digitais foi possível realizar a interpolação dessas informações o que possibilitou a confecção da carta temática de Uso do Solo o que possibilitou realizar a análise e interpretação do modelo de ocupação do espaço geográfico.

Com base nessas informações foram localizadas no modelado da área em questão dez principais zonas de risco para população (Liberdade, Heliópolis, Novo Heliópolis, Parque Fênix, COHAB III, São José, Barreira do Inferno, Santo Antônio, Jardim Petrópolis e Magano) devido o alto nível de instabilidade das encostas, as quais são ocupadas por residências, utilizadas para práticas econômicas de subsistência (Agricultura familiar, criação de animais de pequeno e médio porte, retirada de argila para olarias...), descarga do esgoto urbano sem o devido tratamento, aproveitado para descarte de resíduos sólidos, são cortadas para ampliar o espaço do lote... 0 conjunto dessas ações insustentáveis está promovendo alterações nas feições e contaminação dos corpos de água, os quais em sua maioria são utilizados para o consumo humano e animal.

O poder público tenta amenizar essa situação com a construção de obras paliativas emergenciais esporádicas (Construção de muros de contenção, ampliação da rede de esgoto, remoção temporária ou permanente da população que ocupa locais com maior probabilidade de deslizamentos ou desmoronamentos...), mas elas surtem pouco efeito nessa dinâmica socioespacial. Já as comunidades tentam minimizar a instabilidade das encostas colocando restos de detritos da construção civil, medida que apenas minimiza temporariamente o problema, logo essa feição não apresenta cobertura vegetal para estabiliza-la. Para os habitantes, o ápice desses problemas ocorre nos meses mais chuvosos que vão de abril a julho, esse intervalo temporal apresenta uma precipitação média de $118,25 \mathrm{~mm}$. Esse alto índice pluviométrico, encharca as encostas desprotegidas e instáveis agravando ainda mais esse cenário. 
Rev. Elet. em Gestão, Educação e Tecnologia Ambiental (e-ISSN: 2236-1170)

Para minimizar os impactos geoambientais no sítio urbano de Garanhuns-PE é necessária a implantação de um modelo de uso e ocupação do solo sustentável, possibilitando, incentivando e subsidiando ações como: pesquisas sobre a morfodinâmica local e suas relações com o sítio urbano, recuperação das áreas verdes com flora local, substituição do saneamento básico pelo saneamento ambiental, alternativas econômicas para as comunidades mais carentes, remanejamento da população das áreas para locais seguros...

Sendo que, para que essas medidas tenham os efeitos desejados é necessário que ocorram de forma conjunta entre a sociedade, o poder público e a comunidade acadêmica. Evitando assim que elas ocorram de maneira inadequada, o que as tornaria pouco eficazes. Um bom exemplo foi o remanejamento de uma parte da população da comunidade da Liberdade para a COHAB III, nessa ação ocorreu apenas à transferência parcial da população, ou seja, o perímetro da encosta instável não foi recuperado nem monitorado. Com isso ele já começa e ser utilizado novamente para atividades econômicas de subsistência e ocupado por pequenas residências.

\section{REFERÊNCIAS BIBLIOGRÁFICAS}

AZAMBUJA R. N. 2007. Análise Geomorfológica em Áreas de Expansão Urbana em Garanhuns-PE. Recife. Dissertação de Mestrado, Departamento de Ciências Geográficas, Universidade Federal de Pernambuco, $154 \mathrm{p}$.

BONUCCELLI, T.; ZUQUETTE, L.V. 1999. Movimentos gravitacionais de massa e erosões na cidade histórica de Ouro Preto, Brasil. Lisboa. Revista Portuguesa de Geotécnica. 85: 59-80.

CÂMARA G.; Davis C.; Monteiro A. M. V. 2001. Introdução á Ciência da Geoinformação. São José dos Campos. Instituto Nacional de Pesquisas Espaciais, $345 \mathrm{pp}$.

CPRM-Companhia de Pesquisa de Recursos Minerais 2005. Diagnóstico do Município de Garanhuns. Recife/PE, 11pp. CPRM-Companhia de Pesquisa de Recursos Minerais 2008. Geologia da Folha de Garanhuns. Brasília/DF, 67pp.

EMBRAPA-Empresa Brasileira de Pesquisa Agropecuária. Brasil em Relevo. Disponível em: <http://www.relevobr.cnpm.embrapa.br/index.htm>. Acesso em 10 de jan. 2012.

GERMANO, P. M. L. \& GERMANO, M. I. S. A água: um problema de segurança nacional. Higiene Alimentar, São Paulo, Brasil, v. 15, p. 15-18, 2001.

GOIS, D. V. 2010. Planejamento Ambiental e o Uso do Geoprocessamento no Ordenamento da Bacia do Rio da Dona-BA. Tese de Doutorado, Núcleo de Pós-Graduação em Geografia, Universidade Federal de Sergipe, 309 p.

IBGE-Instituto Brasileiro de Geografia e Estatística. Banco de Dados. Disponível em: <http://www.ibge.gov.br/home/default.php>. Acesso em 20 de mar. 2012.

INMET-Instituto Nacional de Meteorologia. Estações e Dados. Disponível em: <http://www.inmet.gov.br/portal>. Acesso em 22 de mai. 2012.

INPE-Instituído Nacional de Pesquisas Espaciais. Catálogo de Imagens. Disponível em: <http://www.dgi.inpe.br/CDSR/>. Acesso em 18 de mar. 2012.

ROSA, P. R. 2005. A relação erosão regressiva e assoreamento no fundo do vale: o caso do açude Namorado em São João do Cariri. Areia. Dissertação de Mestrado, Centro de Ciências Agrárias, Universidade Federal da Paraíba, 60 p. SANTOS, R. F. Planejamento ambiental: teoría e prática. São Paulo: Editora Oficina de Textos, 2004. 